\title{
Metodologias ativas e interdisciplinaridade na formação do nutricionista
}

\section{Active methodologies and interdisciplinarity training on the formation of nutritionists}

\author{
Josiele Cristine Ribeiro dos Santos ${ }^{1}$, Kerili Maia da Rocha ${ }^{2}$, Andrea Maria Baroneza ${ }^{3}$, \\ Deberli Ruiz Fernandes ${ }^{4}$, Viviane Valle de Souza ${ }^{5}$, José Eduardo Baroneza ${ }^{6}$
}

\section{Resumo}

No ensino superior, as metodologias ativas são alternativas a aulas expositivas e visam formar profissionais proativos e capacitados a trabalhar em equipe. $\mathrm{O}$ objetivo deste trabalho foi avaliar a motivação e a percepção de aprendizagem de 68 alunos matriculados em 2015 no primeiro ano do curso de Nutrição da Universidade Positivo, submetidos a aulas expositivas e à metodologia ativa adaptada de aprendizagem baseada em problemas e em projetos (ABPP) por meio de questionários e comparação estatística. Em nossos resultados não foram observadas diferenças significativas quanto à motivação e percepção de aprendizagem, no ponto de vista dos alunos. Entretanto, os alunos que responderam ao questionário após a metodologia ativa perceberam maior convergência entre as disciplinas envolvidas $(p<0.05)$. Concluímos que o uso de metodologias ativas e da interdisciplinariedade provocou no aluno uma melhor percepção na relação que existe entre disciplinas de formação básica e profissionalizantes. Termos de indexação: Metodologias ativas. Interdisciplinaridade. Ensino superior.

\begin{abstract}
In higher education, active methodologies are alternatives to lectures to train proactive and capable professionals to work in teams. The aim of this study was to evaluate the motivation and the perception of learning of 68 students enrolled in 2015 in the first year of Nutrition course of the Positivo University, submitted to lectures and the adapted active methodology of problem-based learning and projects through Questionnaires and statistical comparison. In our results there were no significant differences in the motivation and perception of learning from the point of view of the students. However, the students who answered the questionnaire after the active methodology perceived greater convergence among the subjects involved $(\mathrm{p}<0.05)$. We conclude that the use of active methodologies and of interdisciplinarity provoked in the student a better perception in the relation that exists between disciplines of basic and professional training.

Indexing terms: Active methodologies. Interdisciplinarity. Higher education.
\end{abstract}

1 Bacharel em Nutrição da Universidade Positivo. E-mail: josieleribeiro2@gmail.com

Bacharel em Nutrição pela Universidade Positivo. E-mail: kerilimaiadarocha@gmail.com

3 Mestre em Engenharia da Produção pela Universidade Federal de Santa Catarina. Professora assistente da Universidade Tecnológica Federal do Paraná. E-mail: andreamabaroneza@gmail.com

4 Biomédica. Mestre em parasitologia pela Universidade Federal do Paraná. Professora assistente da Universidade Positivo. E-mail: deberlifernandes@gmail.com

5 Bacharel em nutrição pela Universidade Federal do Paraná. Especialista em Formação Pedagógica do Professor Universitário pela Pontifícia Universidade Católica do Paraná. E-mail: vivianevs1@hotmail.com

6 Doutor em Biologia Celular e Molecular pela Universidade Federal do Paraná. Professor Adjunto da Universidade Positivo.Email: jbaroneza@gmail.com 


\section{Introdução}

Atualmente, o ensino superior tem sido pressionado por mudanças metodológicas no sentido de formar profissionais proativos e capacitados a trabalhar em equipe, que sejam instrumentos de transformação social e que estejam conscientes e habilitados a se adaptar às rápidas transformações que o mundo passa. No Brasil, a maioria dos cursos superiores da área da saúde possuem currículos apoiados na metodologia tradicional de ensino, compostos por disciplinas diversificadas que contemplam temas de formação básica, técnica e clínica, ofertadas de modo semestral ou anual. Entretanto, sobretudo nos primeiros anos dos cursos, a distribuição de conteúdos específicos em disciplinas isoladas e a ausência de atividades inter e transdisciplinares dificultam a aprendizagem e a motivação dos alunos, que frequentemente não compreendem a relação entre os conteúdos abordados e o exercício da profissão (GARCIA et al., 2007).

Quando as disciplinas interagem entre si produzem relações que tendem a ser convergentes, contribuindo para a motivação e para a aprendizagem do aluno (ALMEIDA FILHO, 2005). Em artigo sobre o processo de ensino para formação de médicos, Garcia et al. (2007), conclui que interdisciplinaridade é uma exigência para a integralidade e, neste sentido, as instituições de ensino superior têmdebatido novos currículos em cursos da saúde, valorizando a interdisciplinariedade e, também, as metodologias ativas.

A interdisciplinaridade na prática deve ter uma linha de ação integradora e agregadora de um objeto de conhecimento. É uma atividade que implica em vontade e compromisso do professor de refletir e elaborar um contexto mais geral onde cada disciplina em contato passa a depender uma da outra. A integração se dá pela relação entre duas ou mais disciplinas resultando em intercomunicação, transformação de metodologias de pesquisa e aperfeiçoamento de conceitos o que necessita de um amplo planejamento prévio e entrosamento entre as disciplinas envolvidas (AUGUSTO; CALDEIRA, 2007). O objetivo é gerar uma aprendizagem significativa e promover transformações na realidade social.

A qualidade do processo pedagógico no ensino superior brasileiro é objeto de avaliações promovidas pelo Ministério da Educação. Em um levantamento realizado no ano de 2004 alunos da área da saúde apontaram como principais problemas neste nível de ensino a falta de articulação entre a teoria e a prática e entre o ciclo básico e clínico, despreparo docente, predomínio da concepção tradicional de ensino baseada na transmissão do conhecimento e na experiência do professor, currículos arcaicos e descontextualizados, entre outros (BRASIL, 2004).

A LDB - Lei de Diretrizes e Bases da Educação Nacional e das DCNs - Diretrizes Curriculares Nacionais vem discutindo e empenhando-se nas mudanças dos currículos, tendo em vista o foco do processo de ensino centrado no aluno como sujeito ativo de sua formação (CONSELHO NACIONAL DE EDUCAÇÃO, 2001). O documento síntese do Seminário Internacional Universidade XXI - Novos Caminhos para a Educação Superior - evidencia a discussão sobre a atualização universitária brasileira e coloca como diretrizes: desenvolver esforço sistemático de diálogo inter e transdisciplinar e integrar conhecimento, educação e produção (BRASIL, 2004).

Os movimentos citados acima corroboram com Menestrina e Moraes (2011), quando citam que é preciso estimular todos os agentes envolvidos na educação para que possam dinamizar seus processos e chegar à qualidade educativa pertinente com as demandas do mundo conectado. As mudanças de perfis profissionais levam a todos os envolvidos a se questionar sobre o caminho da universidade, sobre este modelo tradicional da escola centrada apenas em conteúdos preestabelecidos e regida por 
uma estrutura curricular estanque, não adaptativa às perspectivas atuais. A realidade universitária evolui, avança e precisa ser atendida por meio do desenvolvimento de habilidades didáticas mais eficazes que envolva ciência, visão de mundo, ser humano e realidade atual, onde o papel do professor é a mediação nos processos de elaboração do conhecimento (BORGES; ALENCAR, 2014).

Neste sentido se apresentam como alternativas as metodologias ativas de ensino, que são descritas como processos interativos de conhecimento, que envolvem análise, estudos, pesquisas e decisões individuais ou coletivas, com a finalidade de encontrar soluções para um problema específico em um processo onde o professor atua como facilitador e orientador para que o aluno atinja objetivos estabelecidos (BERBEL, 2011).

Entre as metodologias ativas mais utilizadas em cursos de saúde estão a aprendizagem baseada em problemas e a aprendizagem baseada em projetos. Na aprendizagem baseada em problemas, os alunos trabalham em grupos para resolver problemas relacionados com atividade profissional futura com apoio do professor e de tutores. Após receber o problema, os alunos se organizam de modo a estabelecer um caminho que leve a elucidação do mesmo. Em encontros subsequentes o professor e os tutores interagem com os alunos e avaliam o progresso dos grupos de acordo com metodologia proposta por Berbel (1998). Fica a cargo do professor o esforço no sentido de gerar e proporcionar modelos e cenários de ensino capazes de conduzir o trabalho e a aprendizagem em níveis de complexidade e relevância adequados (ROCHA; LEMOS, 2014).

$\mathrm{Na}$ aprendizagem baseada em projetos, os alunos recebem um projeto a ser elaborado e são orientados pelo professor e por tutores em seu processo de aprendizagem por meio de interrogatórios que os leva a experiência de aprendizagem. As conversas ocorridas em sessões de aula, entre alunos e o professor, alcançam detalhes significativos por serem conduzidas de forma semelhante ao que seria feito na vida profissional. Ao longo do processo os alunos tomam decisões que envolvem o desenvolvimento da ideia o projeto, decisão do escopo do projeto, seleção dos padrões, incorporação dos resultados simultâneos, desenvolvimento a partir da formulação do projeto e criação do melhor ambiente de trabalho (MARKHAM; LARMER; RAVITZ, 2008).

De acordo com Masson et al. (2012) a aprendizagem por projetos favorece a relação dos diversos conteúdos facilitando aos alunos à construção de seus conhecimentos com a integração dos diferentes saberes disciplinares, numa filosofia interdisciplinar em busca de uma aprendizagem significativa. Projetos e problemas podem estar associados no processo de ensino-aprendizagem numa visão interdisciplinar. Procedimentos metodológicos como estes propiciam o acesso a maneiras diferenciadas de aprender e são alternativas ao modelo tradicional uma vez que imergem o aluno, sujeito da aprendizagem, no processo da busca pelo conhecimento, ao encontro do que é sugerido por Freire (1996).

Neste sentido, o objetivo desse trabalho foi verificar a motivação e a percepção de aprendizagem em alunos matriculados em 2015 no primeiro ano do curso de Nutrição da Universidade Positivo, submetidos a aulas expositivas tradicionais e à metodologia ativa adaptada de aprendizagem baseada em problemas e em projetos. A aprendizagem baseada em problemas e a aprendizagem baseada em projetos estão entre as metodologias inovadoras mais empregadas e defendidas no mundo acadêmico; a primeira é aquela na qual o aluno assume uma posição ativa frente ao conhecimento; a segunda é aquela em que, sob tutoria do professor, o aluno deve desenvolver um projeto com autonomia (BEHRENS, 2001; OLIVEIRA; VENTURA, 2005; SILVEIRA, 2006). 


\section{Metodologia}

Neste estudo descritivo foram analisados questionários respondidos de forma voluntária por 68 alunos do curso de nutrição da Universidade Positivo, com a finalidade de comparar a motivação e a percepção de aprendizagem duas diferentes práticas pedagógicas: 1. Metodologia de ensino tradicional de aulas expositiva; e 2. Metodologia ativa interdisciplinar adaptada de aprendizagem baseada em problemas e em projetos (ABPP). Este trabalho envolveu as disciplinas de biomorfologia, agentes agressores e técnica dietética, ofertadas no primeiro ano do curso de graduação.

Todos os alunos foram submetidos ambas as metodologias de ensino. Para que não houvesse tendenciosidade nas respostas, os alunos foram selecionados aleatoriamente e divididos em dois grupos: o primeiro grupo (G1) foi composto por 38 alunos que responderam o questionário após aulas expositivas tradicionais, enquanto o segundo grupo (G2) foi constituído por 30 alunos que responderam o mesmo questionário após ter passado pela atividade interdisciplinar envolvendo ABPP.

Para a atividade interdisciplinar foi elaborada uma apostila com 15 casos visando à reflexão, o estudo e a discussão de temas que envolviam as disciplinas relacionadas. Os casos foram redigidos de modo a representar um conjunto de situações comuns que profissionais nutricionistas encontram no exercício da profissão e eram acompanhados de questões com objetivo de direcionar o estudo e de suscitar reflexões e diálogo. Ressaltamos que não foram ministradas aulas teóricas prévias sobre os temas abordados em cada caso. Após responder as questões, os alunos precisavam simular o caso num projeto cujo resultado devia ser fotografado e apresentado à comunidade acadêmica. Segue abaixo um exemplo de caso desenvolvido para o projeto:

\section{CASO: As estranhas amêndoas laminadas}

Juliano é doceiro e confeiteiro e tem muita experiência na preparação de doces de inspiração árabe. Uma de suas freguesas pediu a Juliano que desenvolvesse um doce exclusivo, com amêndoas laminadas, para uma festa que daria em breve. Juliano comprou as amêndoas, testou suas idéias, desenvolveu uma receita autoral, e armazenou as oleaginosas em um pote plástico à espera da encomenda. Seis meses depois, ao receber a encomenda, Juliano constatou que as amêndoas estavam diferentes de quando comprou, escurecidas. Pensou então que estivessem fora do prazo para consumo e efetuou uma nova compra. Baseado no caso acima descrito responda as questões abaixo e desenvolva o projeto que segue:

1) Qual seria o principal motivo dessa oleaginosa estar com esse aspecto? Por quê?

2) Como deve ser feito o armazenamento desses alimentos?

3) O consumo da amêndoa no estado observado por Juliano poderia resultar em problemas de saúde? Se sim, quais?

4) Desenvolva um projeto que simule o que acontece com as oleaginosas em diferentes tempos e condições de armazenamento e observe-as utilizando um estereomicroscópio. Fotografe os resultados obtidos.

5) Desenvolvaumpôstercom título, introdução, objetivos, metodologia, resultados, considerações finais e referências para expor na semana acadêmica de Nutrição.

Para desenvolver este trabalho, os discentes foram divididos em equipes que variaram de 5 a 6 
alunos. Cada equipe se organizou de modo a ter um líder, um redator e um porta voz e se responsabilizou por um caso diferente. Foram agendados 6 encontros que envolveram pesquisa, reflexão, respostas das questões diretivas e conclusão do projeto. Nos encontros os alunos eram orientados pelo professor e por 2 tutores.

No encontro destinado à leitura e discussão inicial dos casos, cada grupo identificou e definiu os conceitos a serem investigados para análise do problema, considerando os conhecimentos prévios de cada membro. Supervisionados pelos professores em encontros posteriores, os alunos tiveram tempo para discussão, pesquisa, elaboração do projeto, análise microscópia, fotografia e montagem dos pôsteres. No decorrer do processo as equipes tiveram à disposição salas com mesas redondas na biblioteca, microscópios acoplados a câmeras e computadores com conexão à internet para pesquisa e montagem dos pôsteres. Os alunos foram avaliados pela equipe de professores e receberam feedback em relação à conclusão de seus projetos-problemas até que os trabalhos estivessem aptos para serem apresentados num evento acadêmico. Cada projeto foi então apresentado, em formato de pôster, na Semana Acadêmica de Nutrição da Universidade Positivo no ano de 2015.

Para a interpretação dos dados obtidos por meio dos questionários de motivação e percepção da aprendizagem, as taxas de respostas foram tabuladas e comparadas utilizando o teste Exato de Fisher (95\% IC).

Esta pesquisa foi aprovada pelo Comitê de Ética em Pesquisa envolvendo Seres Humanos da Universidade Positivo de acordo com as atribuições definidas na Resolução CNS 196/96, datada em 03 de julho de 2015 sob o parecer número 45494715.0.0000.0093.

\section{Resultados e Discussão}

Os 68 alunos foram divididos em dois grupos categorizados da seguinte forma: G1 representa o grupo de alunos que opinaram após aulas expositivas tradicionais $(\mathrm{n}=38)$ e, G2 representa o grupo de alunos que opinaram após atividades interdisciplinares baseadas em metodologias ativas $\operatorname{ABPP}(\mathrm{n}=30)$.

De acordo com nossos resultados, o nível de importância para a formação dos nutricionistas atribuída pelos alunos às disciplinas de biomorfologia, agentes agressores e técnica dietética, não variou quando comparados o padrão de respostas dos alunos nos grupos G1 e G2 ( $>0.05)$ (Tabela 1). Entretanto, a análise isolada de cada taxa mostrou a tendência de atribuição de maior importância às disciplinas após a atividade interdisciplinar baseadas em metodologias ativas, uma vez que em G2 nenhum aluno vinculou a biomorfologia à variável pouco importante, bem como um aumento na porcentagem de alunos que considerou agentes agressores e técnica dietética como disciplinas muito importantes.

Alberti, Furtado e Kipper (2015) destacam que a fragmentação e isolamento das disciplinas ministradas no ensino universitário são um problema que merece atenção, e que, as metodologias ativas de ensino estimulam o educando a se aprofundar em problemáticas do mundo. As estruturas cognitivas são alteradas naqueles que aprendem, os conceitos preexistentes são modificados e novas ligações entre conceitos são promovidas, conduzindo para a formação diferenciada do profissional. 
Tabela 1 - Nível de importância atribuída às disciplinas de biomorfologia, agentes agressores e técnica dietética, na visão de alunos de graduação do primeiro ano de Nutrição, Universidade Positivo, 2015. Os valores estão expressos em porcentagem de respostas e o $p$ se deve à probabilidade calculada por meio do teste Exato de Fisher (95\% IC).

\begin{tabular}{|c|c|c|c|}
\hline Grupos participantes & G1 & G2 & $P$ \\
\hline \multicolumn{4}{|l|}{ Biomorfologia } \\
\hline Muito importante & $39 \%$ & $37 \%$ & \multirow{3}{*}{0.18} \\
\hline Importante & $50 \%$ & $63 \%$ & \\
\hline Pouco importante & $11 \%$ & $0 \%$ & \\
\hline \multicolumn{4}{|l|}{ Agentes agressores } \\
\hline Muito importante & $45 \%$ & $70 \%$ & \multirow{3}{*}{0.05} \\
\hline Importante & $52 \%$ & $27 \%$ & \\
\hline Pouco importante & $3 \%$ & $3 \%$ & \\
\hline \multicolumn{4}{|l|}{ Técnica Dietética } \\
\hline Muito importante & $92 \%$ & $93 \%$ & \multirow{3}{*}{1} \\
\hline Importante & $8 \%$ & $7 \%$ & \\
\hline Pouco importante & $0 \%$ & $0 \%$ & \\
\hline
\end{tabular}

Fonte: Dados da pesquisa

No que se refere à motivação para realização de trabalhos multidisciplinares em comparação com a motivação para trabalhos em disciplinas isoladas, a maioria dos alunos preferiram trabalhos multidisciplinares. A análise estatística indicou que não houve diferença em relação ao padrão de respostas relacionadas a esta variável antes (G1) e após (G2) a atividade interdisciplinar nos moldes da ABPP. Resultados similares foram observados comparando a motivação para trabalhos em equipe em relação aos trabalhos individuais (Tabela 2). Estas variáveis foram avaliadas em razão de que trabalhos em equipe e multidisciplinares são muito valorizados nas metodologias ativas de ensino e constituem um desafio tanto para os alunos quanto para os professores.

Borges e Alencar (2014) comentam sobre o assunto mostrando que a realidade universitária evolui, avança e precisa ser atendida por meio do desenvolvimento de habilidades didáticas ampliadas, mais eficazes que envolva ciência, visão de mundo, ser humano e realidade atual, onde o papel do professor é a mediação nos processos de elaboração do conhecimento. 
Tabela 2 - Motivação na realização de trabalhos acadêmicos entre alunos de graduação do primeiro ano de Nutrição, Universidade Positivo, 2015. G1 e G2 representam alunos que opinaram após aulas expositivas tradicionais ( $\mathrm{n}=38$ ) e após a atividade interdisciplinar proposta $(n=30)$, respectivamente. Os valores estão expressos em porcentagem de respostas e o $p$ se deve à probabilidade calculada por meio do teste Exato de Fisher (95\% IC).

\begin{tabular}{|c|c|c|c|}
\hline Grupos participantes & G1 & G2 & $p$ \\
\hline \multicolumn{4}{|c|}{ Trabalhos interdisciplinares $\mathrm{X}$ em disciplinas isoladas } \\
\hline Mais motivante & $55 \%$ & $70 \%$ & \multirow{3}{*}{0.18} \\
\hline Igualmente motivante & $8 \%$ & $7 \%$ & \\
\hline Menos motivante & $37 \%$ & $23 \%$ & \\
\hline \multicolumn{4}{|c|}{ Trabalhos em equipe $X$ individuais } \\
\hline Mais motivante & $58 \%$ & $37 \%$ & \multirow{3}{*}{0.50} \\
\hline Igualmente motivante & $29 \%$ & $37 \%$ & \\
\hline Menos motivante & $13 \%$ & $26 \%$ & \\
\hline
\end{tabular}

Fonte: Dados da pesquisa

Também comparamos a percepção de das taxas de respostas nos permite observar um aprendizagem em alunos submetidos a atividades interdisciplinares e à atividades em disciplinas isoladas (Tabela 3). Embora não encontramos diferença significativa entre os grupos, a análise aumento na taxa de alunos que responderam que aprendem menos em atividades interdisciplinares após passarem pela atividade da ABPP.

Tabela 3 - Percepção de aprendizagem após a realização de atividades acadêmicas interdisciplinares comparadas a atividades em disciplinas isoladas, na visão de alunos de graduação do primeiro ano de Nutrição, Universidade Positivo, 2015. G1 e G2 representam alunos que opinaram após aulas expositivas tradicionais ( $n=38)$ e após a atividade interdisciplinar proposta $(\mathrm{n}=30)$, respectivamente. Os valores estão expressos em porcentagem de respostas e o $p$ se deve à probabilidade calculada por meio do teste Exato de Fisher $(95 \%$ IC).

\begin{tabular}{lcccc}
\hline Grupos participantes & G1 & G2 & \multicolumn{1}{c}{$\boldsymbol{P}$} \\
\hline Aprendo mais & $63 \%$ & $66 \%$ & \\
Aprendo igual & $37 \%$ & $24 \%$ & 0.09 \\
Aprendo menos & $0 \%$ & $10 \%$ & \\
\hline
\end{tabular}

Fonte: Dados da pesquisa.

A interdisciplinaridade no ensino superior ocorre a partir da integração de disciplinas isoladas na abordagem de temas convergentes. Neste sentido, promover o diálogo entre disciplinas de formação básica e profissionalizantes pode influenciar a percepção do aluno quanto à importância de cada uma em seu processo de aprendizagem. Além disso, por meio de atividades interdisciplinares, os alunos se sentem mais motivados para o estudo e compreendem melhor os assuntos abordados em sua complexidade. Um estudo realizado por Roquete et al. (2012) nos mostra que a abordagem interdisciplinar de temas convergentes é importante tanto na teoria quanto na prática e estimula a vinculação dos múltiplos saberes. 
Em paralelo, trabalhos realizados em grupos visam promover a reflexão, o diálogo, o embate de ideias, a socialização, a formação de lideranças e o amadurecimento dos estudantes, capacitandoos a atuar em conjunto com outros profissionais no mercado de trabalho, a dividir opiniões e a aceitar críticas, características de grande valor nas relações de trabalhos atuais. A realização destes trabalhos resulta em aquisição progressiva de autonomia e maturidade. Entretanto, enquanto não houver maturidade, é comum que após a realização desta modalidade de trabalho os alunos se sintam frustrados, uma vez que a necessidade do diálogo entre personalidades divergentes pode levar a discordância.

Neste processo de amadurecimento é comum que os alunos se sintam desafiados, inseguros e tenham dificuldade em dinamizar e articular os pensamentos do grupo, constituindo um problema a ser vencido pelos estudantes com tutoria do professor (SILVA; ASSIS; GENTILE, 2005; FREITAS et al., 2009)). Os alunos envolvidos neste estudo cursam o primeiro ano de graduação e são provenientes, em maioria, de escolas que privilegiam as metodologias tradicionais e a realização de trabalhos individuais. Sugerimos que as experiências prévias de nossos alunos, bem como a falta de maturidade para trabalhar em grupos, justificam o fato de que os estudantes que passaram pela atividade interdisciplinar proposta em nosso estudo relataram uma pior percepção de aprendizagem após o trabalho em grupo.

Conscientes das dificuldades, mas seguros do benefício ao longo do processo de formação, estimulamos professores de ensino superior a valorizarem os trabalhos interdisciplinares e em grupo, bem como as metodologias ativas de ensino, em todos os anos de graduação. A vivência desse caminho metodológico pelos alunos permite a aquisição do conhecimento por meio do confrontamento com situações vivenciadas no mercado de trabalho e com as atividades inerentes de cada etapa do processo ativo de aprendizagem. De acordo com Freitas et al. (2009), é preciso uma nova configuração do processo de ensino superior, que seja marcada pela autonomia, pela interdisciplinaridade e pela ampliação da liberdade de trajetória dos estudantes.

De acordo com nossos resultados, após a metodologia proposta, um número maior de alunos observou transversalidade entre os temas abordados pelas disciplinas de biomorfologia e agentes agressores, do ciclo básico, e técnica dietética, do ciclo profissionalizante (Tabela 4). O resultado da comparação entre os grupos foi significativo ( $p=0.02)$ após análise estatística pelo teste Exato de Fisher (95\%IC)

Tabela 4 - Existência de pontos em comum entre as disciplinas de biomorfologia, agentes agressores e técnica dietética, na visão de alunos de graduação do primeiro ano de Nutrição, Universidade Positivo, 2015. G1 e G2 representam alunos que opinaram após aulas expositivas tradicionais $(\mathrm{n}=38)$ e após a atividade interdisciplinar proposta $(\mathrm{n}=30)$, respectivamente. Os valores estão expressos em porcentagem de respostas e o $p$ se deve à probabilidade calculada por meio do teste Exato de Fisher (95\% IC).

\begin{tabular}{lcccc}
\hline Grupos participantes & G1 & G2 & & P \\
\cline { 1 - 2 } Há pontos em comum & $68 \%$ & $90 \%$ & \\
Não há pontos em comum & $13 \%$ & $0 \%$ & 0.02 \\
Talvez exista pontos em comum & $19 \%$ & & $10 \%$ & \\
\hline
\end{tabular}

Fonte: Dados da pesquisa 
A transversalidade na formação profissional deve ser considerada e experimentada como um processo social na vida acadêmica cotidiana de estudantes e professores, devendo se efetivar no conjunto das disciplinas e das atividades curriculares (COMERLATTO, 2008). As duas dimensões a serem transformadas pela transversalidade envolvem questões ligadas aos aspectos macrossociais e às atitudes pessoais, assim, o ensino e a aprendizagem precisa ser planejada a partir de conteúdos relativos que exijam a reflexão e amadurecimento interrogativo sobre a vida humana e a realidade construída. (BRASIL, 1998).

Ressaltamos que os resultados de nosso estudo mostram que as práticas de atividades interdisciplinares nos moldes da ABPP desempenham um papel importante na percepção de transversalidade entre disciplinas de formação básica e técnica. Leite e Medina (2001), acentuam que no cotidiano pedagógico a interdisciplinaridade e a transversalidade são simultâneos, seus objetivos de conhecimento estão inter-relacionados. Este resultado pode ser compreendido como um reflexo do esforço de convergir realizado pelo conjunto de professores, mas também está associado à metodologia ativa empregada na atividade. Em estudo de Reeve (2009), o autor enfatiza que o uso de metodologias ativas contribui para que os alunos se tornem proativos na busca pelo conhecimento e isso aumenta a percepção de transversalidade entre temas ministrados por diferentes disciplinas.

Por fim, avaliamos o ponto de vista dos alunos a respeito da importância de aulas práticas nas disciplinas de formação básica. Esta análise foi motivada porque a atividade proposta envolveu duas disciplinas de formação básica, biomorfologia e agentes agressores, e práticas de microscopia. Em nossos resultados constatamos que após a atividade interdisciplinar de ABPP aumentou o número de alunos que consideram as práticas nas disciplinas básicas muito importantes, $60 \%$, em comparação com a opinião dos alunos antes de passar pela atividade, $45 \%$. Entretanto, ao analisar o conjunto dos dados obtidos, considerando todas as opções de respostas, a diferença entre os grupos G1 e G2 não foi significativa (TABELA 5).

Tabela 5 - Importância atribuída às aulas práticas em disciplinas de formação básica na visão de alunos de graduação do primeiro ano de Nutrição, Universidade Positivo, 2015. G1 e G2 representam alunos que opinaram após aulas expositivas tradicionais $(n=38)$ e após a atividade interdisciplinar proposta $(n=30)$, respectivamente. Os valores estão expressos em porcentagem de respostas e o $p$ se deve à probabilidade calculada por meio do teste Exato de Fisher (95\% IC).

\begin{tabular}{lcccc}
\hline Grupos participantes & G1 & G2 & & $\boldsymbol{P}$ \\
\hline Muito importante & $45 \%$ & $60 \%$ & \\
Importante & $53 \%$ & & $40 \%$ & \\
Pouco importante & $2 \%$ & 0.39 & \\
\hline
\end{tabular}

Fonte: Dados da pesquisa

Alberti, Furtado e Kipper (2015) comentam sobre a importância das aulas práticas realizadas por meio das metodologias ativas de ensino que estimulam o educando a se aprofundar em problemáticas do mundo, relacionando as ciências e a vivência - modelo atividade-experiência. Por este modelo os conteúdos de aprendizagem são inseridos em contextos significativos auxiliando na superação da dicotomia existente entre a formação acadêmica e a realidade - teoria e prática. 
Acreditamos que aulas práticas podem despertar a curiosidade e consequentemente o interesse do aluno. Além disso, de acordo com Borges (2002), nessas aulas os alunos têm a oportunidade de interagir com instrumentos específicos de análise que justificam os assuntos abordados na teoria, contribuindo para que o aluno atribua significado aos temas abordados em sala de aula convencional.

Além das questões objetivas, permitimos que os alunos opinassem a respeito da atividade prática integrada. Entre as opiniões constavam:

"É estimulante e ao mesmo tempo desafiador trabalhar com metodologias ativas em grupos, onde as opiniões por vezes são diferentes, isso me fez aprender mais do que se em uma aula tradicional"

"Percebi que existe relação entre as disciplinas. Uma dependia do conhecimento da outra. Foi trabalhoso mas houve ganho na aprendizagem"

"Achei muito interessante pois além de ter integrado as matérias, também integrou a parte técnica com a teórica"

A ABPP dispõe de objetivos educacionais amplos, sustentada sob uma base de conhecimentos estruturada envolvendo problemas reais e integrada com o desenvolvimento de habilidades de aprendizagem autônoma e de trabalho em equipe, contribuindo com a formação do pensamento crítico e criativo em trabalhos em equipe e o compromisso com o aprendizado (RIBEIRO, 2008). Quando empregada no ensino superior, o método ativo de ensino insere o aluno em uma realidade próxima ao que enfrentará no mundo profissional (BOROCHOVICIUS; TORTELLA, 2014).

As metodologias ativas podem utilizar a problematização como estratégia de ensino/ aprendizagem, com o objetivo de alcançar e motivar o discente, pois diante do problema, ele se detém, examina, reflete, relaciona com a sua história e passa a ressignificar suas descobertas. Aprender por meio da problematização e/ou da resolução de problemas de sua área é uma das possibilidades de envolvimento ativo dos alunos em seu próprio processo de formação (MITRE et al., 2008).

\section{Conclusões}

Por meio deste trabalho concluímos que, do ponto de vista dos alunos, a motivação ao aprender e a percepção de aprendizado após aulas no modelo da metodologia ativa da ABPP não são prejudicadas na comparação com a metodologia de aulas expositivas tradicionais. Além disso, o uso da estratégia ativa de ensino numa atividade interdisciplinar envolvendo disciplinas de formação básica e técnica provocou um aumento no número de alunos que entendem a convergência entre as disciplinas, o que corrobora com o que ditam Borges e Alencar (2014) ao destacarem que o processo do aprender conduzido a partir das metodologias ativas costumam conduzir a formação crítica de futuros profissionais nas mais diversas áreas. Outro ponto relevante que ficou claro na pesquisa realizada com os alunos foi o despertar para a autonomia dos estudos, uma prática fora do comum quando utilizada a metodologia das aulas expositivas. Novamente, os autores reforçam o despertar da curiosidade e consequentemente a autonomia e o estímulo à tomada de decisões individuais e coletivas um resultado essencial alcançado pelas metodologias ativas em contextos do estudante com a sua prática social.

Trabalhos anteriores relataram que o uso de metodologias ativas interdisciplinares na formação de profissionais da área da saúde pode trazer melhorias no que se refere a motivação e à percepção de aprendizagem, quando comparadas com a aula expositiva tradicional e acreditamos que tais estratégias podem ser utilizadas de modo seguro em currículos de cursos da saúde, promovendo a interação entre conteúdos formativos e a prática profissional e estimulando a formação de indivíduos proativos, que apresentam uma visão generalista, critica e reflexiva. 
Segundo Berbel (2011) é por meio da educação que se desenvolve a formação da autonomia intelectual do cidadão. A autonomia é condição para que ele possa intervir por meio de ações criativas sobre a realidade e transformá-la. Melo e Sant'Ana (2012), também comentam sobre este assunto e acentuam que o maior desafio é aperfeiçoar a autonomia individual, já que o aluno não está acostumado com este novo modelo pedagógico e, assim, como observado nos resultados dessa pesquisa, se assustam com a exigência de mudança de postura, necessária pelo uso das metodologias ativas e, a criticam pelo fato de terem que sair de sua zona de conforto, situação conduzida pelo professor no uso excessivo das aulas expositivas. Complementam os autores que, o uso das metodologias ativas confronta o ensino tradicional das faculdades.

\section{Referências}

ALBERTI, R. A.; FURTADO, J. C.; KIPPER, L. M. Simulação como ferramenta no ensino de engenharia: problematização e promoção da vivência em processos produtivos. Revista de Ensino de Engenharia, São Paulo, v. 83, n. 1, 2015.

ALMEIDA FILHO, N. Transdisciplinaridade e o paradigma pós-disciplinar na saúde. Saúde e Sociedade, São Paulo, v. 14, n. 3, p. 30-50, 2005.

AUGUSTO, T. G. S.; CALDEIRA, A. M. A. Dificuldades para a implantação de práticas interdisciplinares em escolas estaduais, apontadas por professores da área de ciências da natureza. Investigações em Ensino de Ciências, Porto Alegre, v. 12, n. 1, p. 139-154, 2007. Disponível em: <http://www.if.ufrgs.br/ienci/artigos/ Artigo_ID165/v12_n1_a2007.pdf $\geq$. Acesso em: 30 jan. 2017.

BEHRENS, M. Aprendizagem por projetos e os contratos didáticos. Revista Diálogo Educacional, Curitiba, v. 2, n. 3, p. 77-96, 2001.

BERBEL, N. A. N. A problematização e a aprendizagem baseada em problemas: diferentes termos ou diferentes caminhos? Interface: Comunicação, Saúde e Educação, Botucatu, v.2, n. 2, mar. 1998.

As metodologias ativas e a promoção da autonomia de estudantes. Semina: Ciências Sociais e Humanas, Londrina, v. 32, n. 1, p. 25-40, jan./jun. 2011.
BORGES, A. T. Novos rumos para o laboratório escolar de ciências. Caderno Brasileiro de Ensino de Física, v. 19, n. 3, p. 291-313, dez. 2002.

BORGES, T. S.; ALENCAR, G. Metodologias ativas na promoção da formação crítica do estudante: o uso das metodologias ativas como recurso didático na formação crítica do estudante do ensino superior. Cairu em Revista, Salvador, ano 3, n. 4, p. 119-143, jul./ ago. 2014.

BOROCHOVICIUS, E.; TORTELLA, J. C. B. Aprendizagem baseada em problemas: um método de ensino-aprendizagem e suas práticas educativas. Ensaio: Avaliação e Políticas Públicas em Educação, Rio de Janeiro, v. 22, n. 83, p. 263-294, 2014.

BRASIL. Ministério da Educação e Cultura. Novos caminhos para educação superior. Brasília, 2004. Disponível em: <http://portal.mec.gov.br/sesu/arquivos/ pdf/novoscaminhoseducacaosuperior.pdf $>$. Acesso em: 30 jan. 2017.

Secretaria de Educação Fundamental. Parâmetros curriculares nacionais: terceiro e quarto ciclos: apresentação dos temas transversais. Brasília: MEC/SEF, 1998.

COMERLATTO, D. Um olhar sobre o ensino da pesquisa: a experiência dos cursos de graduação em serviço social da região sul. 2008. 203 f. Tese (Doutorado em Serviço Social) - Pontifícia Universidade Católica do Rio Grande do Sul, Porto Alegre, 2008.

CONSELHO NACIONAL DE EDUCAÇÃO. Diretrizes curriculares nacionais: educação básica. Brasília: Conselho Nacional de Educação, 2001. Disponível em: $<$ http://www.dominiopublico.gov.br/download/texto/ me002630.pdf>. Acesso em 30 jan. 2017.

FREIRE, P. Pedagogia da autonomia: saberes necessários à prática educativa. São Paulo: Paz e Terra, 1996.

FREITAS, V. P. et al. Mudança no processo ensinoaprendizagem nos cursos de graduação em odontologia com utilização de metodologias ativas de ensino aprendizagem. Revista da Faculdade de Odontologia, Londrina, v. 14, n. 2, p. 163-167, maio/ago. 2009.

GARCIA, M. A. A. et al. A interdisciplinaridade necessária para a formação médica. Revista Brasileira de Educação Médica, Rio de Janeiro, v. 31, n. 2, p. 147-155, 2007.

LEITE, A. L. T. A.; MEDINA, N. M. Educação ambiental: curso básico a distância: educação e educação ambiental II. Brasília: MMA, 2001. v. 5.

MARKHAM,T.;LARMER, J.; RAVITZ, J.Aprendizagem baseada em projetos: guia para professores de ensino fundamental e médio. Porto Alegre: Artmed, 2008. 
MASSON, T. J. et al. Metodologia de ensino: aprendizagem baseada em projetos (PBL). CONGRESSO BRASILEIRO DE EDUCAÇÃO EM ENGENHARIA - COBENGE, 40., Belém, 2012. Anais... Belém: ABENGE, 2012. Disponível em: <http://198.136.59.23 9/ abengeorg/CobengeAnteriores/2012/artigos/104325. pdf $>$. Acesso em: 30 jun. 2016.

MELO, B. C.; SANT'ANA, G. A prática da metodologia ativa: compreensão dos discentes enquanto autores do processo ensino aprendizagem. Comunicação em Ciências da Saúde, Brasília, v. 4, n. 23, p. 327-339, 2012.

MENESTRINA, T. C.; MORAES, A. F. Alternativas para uma aprendizagem significativa em engenharia: curso de matemática básica. Revista de Ensino de Engenharia, São Paulo, v. 30, n. 1, p. 52-60, 2011. Disponível em: $<$ http://www.abenge.org.br/revista/index.php/abenge/ article/view/97/77> . Acesso em: 30 jun. 2016.

MITRE, S. M. I. et al. Metodologias ativas de ensinoaprendizagem na formação profissional em saúde: debates atuais. Ciência e Saúde Coletiva, Rio de Janeiro, v. 13, s. 2, p. 2133-2144, 2008.

OLIVEIRA, L. A; VENTURA, P. C. S. A prática da aprendizagem por projetos em três óticas diferentes. Educação \& Tecnologia, Curitiba, v. 10, n. 2, p. 22-28, 2005.

REEVE, J. Why teachers adopt a controlling motivating style toward students and how they can become more autonomy supportive. Educational Psychologist, Hillsdale, v. 44, n. 3, p. 159-175, 2009.
RIBEIRO, L. R. C. Aprendizado baseado em problemas. São Carlos: UFSCAR; Fundação de Apoio Institucional, 2008.

ROCHA, H. M.; LEMOS, W. M. Metodologias ativas do que estamos falando? Base conceitual e relato de pesquisa em andamento. In: SIMPÓSIO PEDAGÓGICO E PESQUISAS EM COMUNICAÇÃO - SIMPED, 9., 2014, Resende. Anais... Resende, 2014. Disponível em: <http://www.aedb.br/wp-content/ uploads/2015/05/41321569>. Acesso em: 16 jan. 2017.

ROQUETE, F. F. et al. Multidisciplinaridade, interdisciplinaridade e transdisciplinaridade: em busca de diálogo entre saberes no campo da saúde coletiva. Revista de Enfermagem do Centro-Oeste Mineiro, Divinópolis, v. 2, n. 3, p. 463-474, 2012.

SILVA, J. L. L; ASSIS, D. L; GENTILE, A. C. A percepção de estudantes sobre a metodologia problematizadora: a mudança de um paradigma em relação ao processo ensino aprendizagem. Revista Eletrônica de Enfermagem, Goiânia, v. 7, n. 1, p. 72-80, 2005.

SILVEIRA, R. P. A medicina de família e comunidade e o ensino de graduação em medicina. metodologias ativas de ensino aprendizagem. Revista Brasileira de Medicina de Família e Comunidade, Rio de Janeiro, supl. 1, p. 215, 2006. 